\title{
EVALUASI SAFETY CRITICAL EVENT PENGEMUDI BUS UNTUK MEMINIMASI KECELAKAAN LALU LINTAS
}

\author{
Manik Mahachandra ${ }^{1^{*}}$, Vania Avviantari ${ }^{2}$ \\ ${ }^{1}$ Departemen Teknik Industri, Fakultas Teknik, Universitas Diponegoro, \\ Jl. Prof. Soedarto, SH, Semarang, Indonesia 50275 \\ ${ }^{2}$ Program Studi Teknik Industri, Fakultas Teknologi Industri, Institut Teknologi Bandung, \\ Jl. Ganesha no 10, Bandung, Indonesia 40132
}

(Received: January 31, 2018/ Accepted: May 31, 2018)

\begin{abstract}
Abstrak
Bus sebagai salah satu moda transportasi darat semakin diminati warga masyarakat dan menjadi salah satu solusi kemacetan di kota-kota besar. Untuk itu, keamanan aktivitas berkendara harus menjadi perhatian. Salah satu aspek penting adalah kondisi kelelahan pengemudi, yang dapat mendorong turunnya tingkat kewaspadaan, sehingga memunculkan safety critical event (SCE). SCE adalah suatu kejadian yang mengharuskan pengemudi mengambil tindakan untuk menghindari kecelakaan, yang dapat dikelompokkan menjadi crash relevant conflict, near-crash, dan crash. Untuk membantu pengambil keputusan dalam upaya menekan risiko kecelakaan lalu lintas, maka penelitian ini dilakukan mengetahui fenomena SCE dan faktor pengaruh SCE pada pengemudi bus. Dengan pengamatan naturalistik, aktivitas 18 orang pengemudi bus diamati selama beberapa hari. Wawancara juga dilakukan terkait aktivitas berkendara sebelumnya. Hasil penelitian menunjukkan bahwa kondisi jalan yang ramai, bentuk jalan yang lurus, dan memiliki banyak persimpangan berhubungan erat dengan frekuensi SCE yang tinggi. Kejadian SCE secara signifikan meningkat pada pukul 10:00-14:00, atau setelah pengemudi bekerja selama lebih dari satu jam. Terakhir, penelitian ini juga menyarankan agar pengemudi diharuskan berhenti sejenak dan beristirahat, masing-masing setelah 1 jam dan 4 jam berkendara untuk menurunkan risiko munculnya kelelahan saat berkendara. Karena itu, penentuan jalur dan penempatan halte dapat diatur untuk menyesuaikan kebutuhan istirahat ini.
\end{abstract}

Kata kunci: Pengemudi bus; Safety critical event; Kondisi jalan; Waktu berkendara; Durasi berkendara

\begin{abstract}
Evaluation of Bus Drivers'Safety Critical Event to Minimize Traffic Accident. Bus has been favorable transportation nowadays, and the number of passangers has been rapidly increase. To ensure the safety on the road, one main aspects that has to be maintained is drivers' physical condition. On some condition, when the alertness level decrease, drivers may experienced safety critical event (SCE) - an event that requires driver to take action to avoid traffic accident, which can be categorized into crash relevant conflict, near-crash, and crash. Therefore, this study aims to explore the SCE phenomenon and factors that related to it. Applying naturalistic study, video data of 18 bus drivers were collected. Interviews were also conducted after each driving activity. Study results showed that roads that were crowded, considerably straight, or had many intersections significantly correlated with highest occurance of SCE. The number of SCE also significantly higher on 10:00-14:00, or when drivers had been driving for more than one hour. Finally, this study suggest that drivers must stop driving and take some rest, each after 1 and 4 hours driving. So that, the bus route and rest areas can be designed to meet this need.
\end{abstract}

Keywords: Bus driver; Safety critical event; Road condition; Time of driving; Driving duration

\footnotetext{
*) Penulis Korespondensi.

e-mail: manik.mahachandra@gmail.com
} 


\section{Pendahuluan}

Angkutan bus semakin diminati masyarakat di kotakota besar. Selain karena biaya perjalanan yang relatif murah, juga karena area jangkauannya cukup luas. Kondisi ini mendapat dukungan penuh pemerintah, mengingat sarana transportasi umum seperti bus menjadi salah satu solusi untuk mengurangi kemacetan di kota besar. Untuk menunjang kemajuan ini, tentu aspek keselamatan penumpang dan pengendara juga harus menjadi perhatian pemerintah.

Salah satu yang terpenting dalam aspek keselamatan adalah memastikan bahwa pengendara selalu dalam kondisi prima saat bekerja. Namun, seringkali hal ini dinomerduakan oleh pihak pengelola angkutan bus. Padahal, sebagaimana yang disimpulkan Biggs et al. (2009), pengemudi bus menghadapi pekerjaan mengemudi dalam lingkungan yang membuat stres dan kinerja menurun sehingga menyebabkan mereka berisiko tinggi mengalami kelelahan. National Transport Commission (2007) mendefinisikan kelelahan sebagai kondisi ketika pengemudi merasa mengantuk, lelah secara fisik maupun mental, atau kekurangan tenaga dalam mengemudi. Kelelahan dapat terjadi karena intensitas dan durasi dari pekerjaan fisik maupun mental.

Pengemudi yang mengalami kelelahan saat berkendara meningkatkan risiko timbulnya kecelakaan lalu lintas (Williamson et al., 2011). Hal ini dikarenakan kelelahan dapat berdampak pada penurunan kewaspadaan (Yassierli et al., 2015), yang pada akhirnya meningkatkan risiko terjadinya kecelakaan serta meningkatkan safety critical event (SCE) (Soccolich et al., 2012). Terlebih lagi, risiko kecelakaan akan meningkat ketika jam kerja dan durasi mengemudi bertambah (Di Milia et al., 2011). Pada akhirnya, kondisi ini dapat berujung pada kerugian material maupun non-material yang fatal, seperti kematian.

Safety critical event merupakan suatu kejadian yang mengharuskan pengemudi untuk mengambil tindakan untuk menghindari kecelakaan (Soccolich et al., 2012). Dengan mengetahui fenomena SCE, beberapa kejadian yang pada akhirnya dapat menyebabkan kecelakaan dapat dihindari. SCE mencakup empat kejadian secara umum, yaitu unintentional lane deviation, crash relevant conflict, near-crash, dan crash (Soccolich et al., 2012). Unintentional lane deviation adalah keadaan dimana kendaraan memasuki jalur lain dimana tidak terdapat objek lain, seperti kendaraan, pembatas jalan, dan lain-lain. Crash-relevant conflict merupakan suatu keadaan dimana pengemudi memberikan respon untuk menghindari kecelakaan, namun manuver yang dilakukan tidak secepat kejadian near-crash. Nearcrash merupakan suatu kejadian hampir celaka yang harus dihindari secara cepat dengan melakukan banting setir. Crash merupakan suatu kejadian ketika kendaraan bersentuhan dengan objek lain, baik yang diam maupun bergerak. SCE dianggap perlu dilihat lebih lanjut karena hal ini sangat berkaitan dengan angka kecelakaan lalu lintas yang meningkat setiap tahunnya.

Sesuai dengan yang dilakukan oleh Soccolich et al. (2012), SCE dapat diamati dengan studi yang bersifat naturalistik, dimana kondisi pengemudi diobservasi secara langsung pada saat berkendara di jalan. Dengan menggunakan pengambilan data secara langsung di lapangan, maka dapat pula diperoleh pula durasi mengemudi, waktu berkendara, maupun faktor lainnya yang terkait secara akurat.

Untuk menjamin kondisi prima pengemudi bus, maka perlu dilakukan pengamatan mendalam mengenai SCE pengemudi bus selama bekerja, terutama mengenai faktor yang dapat mempengaruhi munculnya SCE tersebut. Berdasarkan penelitian oleh Soccolich et al. (2012), durasi mengemudi mempengaruhi banyaknya SCE yang terjadi. Waktu berkendara juga dapat berpengaruh pada kewaspadaan pengemudi (Yassierli et al., 2015), tingkat kantuk selama mengemudi (Mahachandra et al., 2009), dan risiko terjadinya kecelakaan di jalan raya (Rail Safety and Standards Board, 2013). Komada et al. (2013) menyebutkan bahwa kondisi jalan yang ramai, khususnya oleh kendaraan lain berpengaruh terhadap tingginya risiko kecelakaan. Selain itu, Kodaka et al. (2003) menyebutkan bahwa 90\% kejadian hampir celaka maupun kecelakaan terjadi di jalan yang lurus. Sebaliknya, usia pengemudi tidak mempengaruhi banyaknya kecelakaan yang terjadi (Tseng, 2011). Oleh karena itu, faktor lokasi kejadian, durasi mengemudi, dan waktu berkendara yang dinilai dapat mempengaruhi SCE perlu diteliti lebih lanjut. Dengan mengetahui keterkaitan faktor tersebut pada pengemudi bus di Indonesia, maka risiko kecelakaan lalu lintas diharapkan dapat berkurang.

\section{Bahan dan Metode}

Penelitian dilakukan dengan metode eksperimen lapangan yang bersifat naturalistik, dimana observasi dilakukan langsung pada saat responden bekerja di kondisi nyata.

\subsection{Responden}

Dua puluh orang pria yang berprofesi sebagai pengemudi bus profesional dilibatkan dalam penelitian ini. Responden dipilih secara acak dari daftar pengemudi bus DAMRI di kota Bandung, Jawa Barat. Kota Bandung dipilih sebagai representasi kota besar di Indonesia. Rute Leuwipanjang-Cicaheum dipilih untuk durasi perjalanan panjang, yaitu 2 hingga 3 jam, sedangkan rute Leuwipanjang-Dipati Ukur dipilih untuk durasi perjalanan pendek, yaitu 1 jam. Dengan dua jenis rute yang berbeda durasinya, maka dapat dilakukan perbandingan terhadap fenomena SCE yang secara teori dipengaruhi oleh durasi mengemudi. Para responden menyetujui keikutsertaannya melalui penandatanganan informed consent

Setiap sebelum dan sesudah kegiatan mengemudi, responden mengisi kuesioner. Dengan kuesioner ini, diharapkan terdapat gambaran kondisi pengemudi dan 
SCE yang terjadi. Selain itu, dilakukan pula pengambilan gambar dan observasi secara langsung saat pengemudi sedang melakukan aktivitas mengemudi. Melalui hasil pengambilan gambar dan observasi secara langsung ini, selain dapat diketahui SCE yang terjadi, juga dapat diketahui faktor-faktor yang dapat mempengaruhi terjadinya SCE tersebut.

\subsection{Variabel Penelitian}

Variabel bebas dan terikat yang terlibat dalam penelitian ini adalah:

a. Durasi mengemudi; sebagai variabel bebas; dihitung mulai dari pengemudi memulai aktivitas berkendara di pool awal sampai pengemudi kembali ke pool tersebut di akhir jam kerja.

b. Waktu pengemudi; sebagai variabel bebas; merupakan waktu setempat saat kejadian SCE muncul.

c. Lokasi kejadian SCE; sebagai variabel bebas; merupakan nama jalan beserta karakteristik jalan raya yang dilalui saat suatu SCE muncul.

d. Safety critical event; sebagai variabel terikat; diamati melalui video pengamatan dengan kamera perekam.

Selain itu, terdapat beberapa variabel yang dikontrol, seperti:

- Jenis kelamin responden; semuanya pria.

- Usia responden; semuanya dalam rentang usia produktif.

- Rute; diambil dua jenis rute, yaitu terpendek dan terpanjang.

\subsection{Pengambilan Data}

Proses pengambilan data terdiri atas beberapa tahapan berikut:

a. Persiapan alat

Sebelum mengemudi di hari pertama pengamatan dilakukan instalasi alat berupa kamera yang dapat digunakan untuk merekam kondisi perjalanan. Kamera diletakkan pada kaca depan bus dan diarahkan ke jalan di depan bus, seperti yang ditunjukkan oleh Gambar 1. Penempatan ini ditujukan agar kejadian SCE dapat terekam dengan jelas, yang umumnya terlihat dari kondisi kendaraan dan pengguna jalan lainnya.

b. Inisiasi

Untuk meminimasi efek kurva belajar (learning curve) para responden penelitian, maka hasil pengamatan pada hari pertama tidak dilibatkan dalam pengolahan data lebih lanjut. Pengamatan hari pertama lebih ditekankan pada pembiasaan alat dan pengisian kuesioner oleh responden.

\section{c. Perekaman SCE}

Kemunculan SCE direkam selama aktivitas mengemudi tersebut dilakukan. Perekaman dilakukan selama dua hari kerja untuk masing-masing responden. d. Kuesioner

Pada hari pertama pengumpulan data, responden diminta mengisi kuesioner mengenai data demografi, seperti usia, lamanya pengalaman mengemudi, dan lain-lain. Sebelum setiap aktivitas mengemudi di hari kedua dan ketiga, responden diminta mengisi kuesioner mengenai hal yang terkait dengan kewaspadaan selama mengemudi, seperti durasi tidur pada malam sebelumnya, jumlah kafein yang dikonsumsi, dan lainlain.

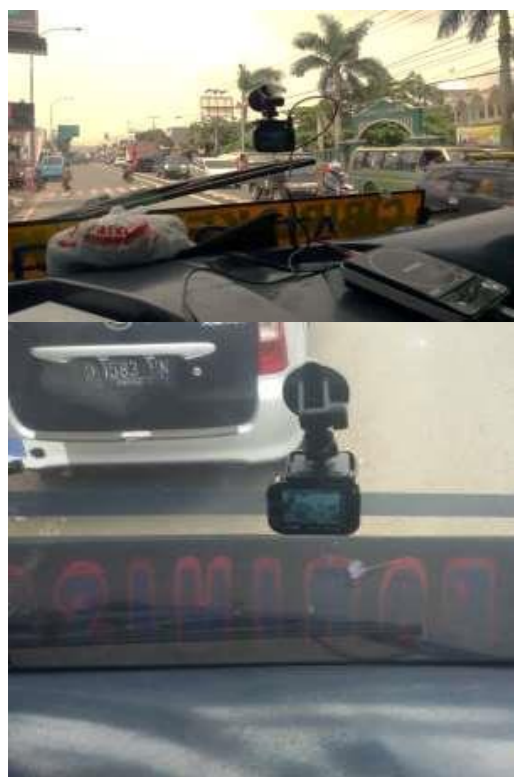

Gambar 1. Instalasi Kamera Perekam pada Dashboard Kendaraan

Setiap setelah mengemudi, responden juga diminta mengisi kuesioner yang menilai kondisi berkendara sebelumnya, seperti kejadian SCE yang muncul, kondisi jalan raya selama berkendara, dan lain-lain.

\subsection{Pengolahan Data}

Safety critical event yang terekam pada kamera pengamat dikelompokkan berdasarkan karakteristik dari tiga jenis SCE berikut:

a. Crash relevant conflict

Secara tiba-tiba terdapat objek lain pada jalur mengemudi, namun dapat dihindari dengan manuver ringan atau pengemudi tidak menjaga jarak dengan kendaraan yang berada di depannya. Pengemudi menghindari objek tersebut dengan melakukan rem mendadak atau mempercepat laju kendaraan atau kombinasi dari keduanya.

b. Near-crash

Secara tiba-tiba terdapat objek lain pada jalur mengemudi atau pengemudi tidak menjaga jarak dengan kendaraan yang berada di depannya. Pengemudi menghindari objek tersebut dengan melakukan banting setir atau rem mendadak. Manuver tersebut dilakukan hingga mencapai batas yang dapat dilakukan kendaraan.

c. Crash

Kendaraan bersentuhan dengan objek lain yang diam maupun bergerak, seperti kendaraan lain, trotoar, pembatas jalan, pejalan kaki, pengemudi sepeda, binatang, atau objek yang berada di jalan maupun luar jalan. 


\section{Hasil dan Pembahasan}

Dua dari dua puluh responden tidak dapat menyelesaikan proses pengumpulan dengan baik akibat kendala teknis. Dengan demikian, hanya data dari 18 orang responden yang kemudian diolah lebih lanjut. Responden tersebut terdiri atas delapan pengemudi rute panjang dan sepuluh orang pengemudi rute pendek. Mereka berusia rata-rata 43,5 tahun, dengan lamanya pengalaman mengemudi rata-rata 15,72 tahun.

Selama pengamatan dapat dikumpulkan 125 kejadian safety critical event. Selanjutnya, SCE yang muncul akan dikelompokkan berdasarkan karakteristiknya, waktu kemunculannya, juga penyebabnya. Hal lain yang terkait dengan kejadian SCE juga akan diteliti pengaruhnya terhadap kemunculan SCE, seperti durasi berkendara dan lokasi kejadian SCE tersebut.

\subsection{SCE Berdasarkan Kategorinya}

Jumlah kejadian SCE yang terekam dalam kamera pengamatan dikelompokkan menjadi crash relevant conflict, near-crash, dan crash. SCE juga dikelompokkan kedalam tiga kategori durasi berkendara, sebagaimana yang tertulis pada Tabel 1.

Tabel 1. Frekuensi SCE Berdasarkan Durasi Berkendara

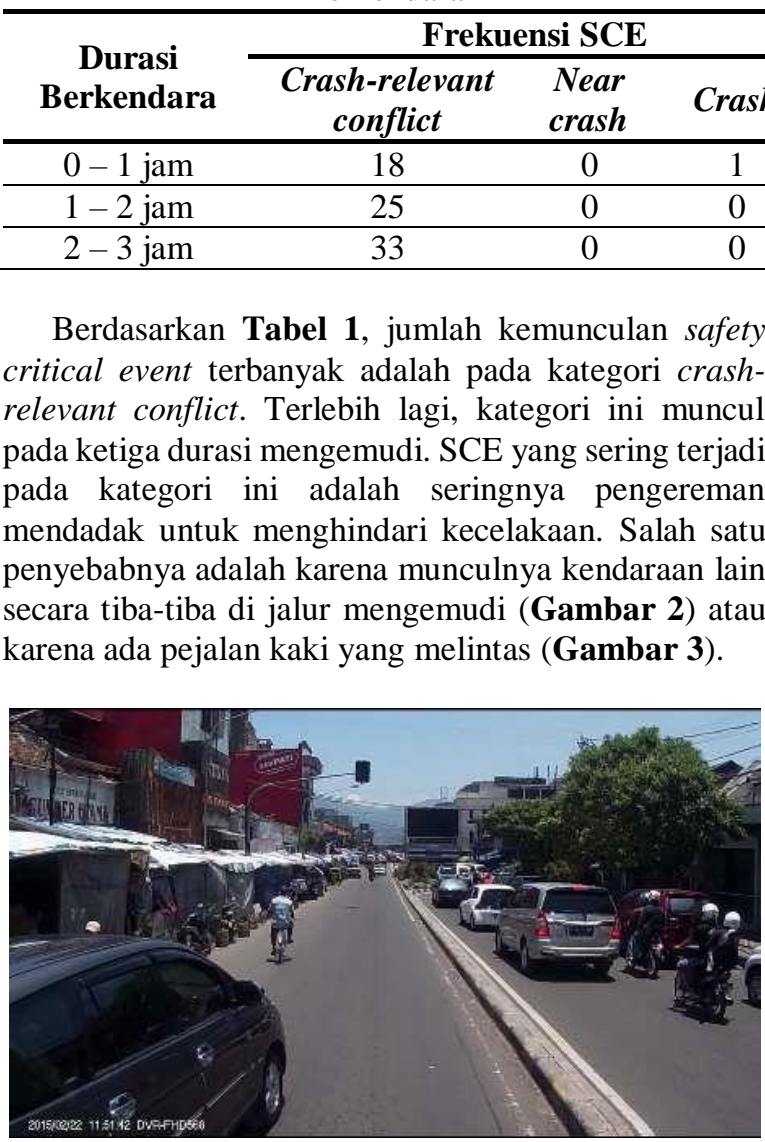

Gambar 2. Contoh Kejadian Crash-relevant Conflict Akibat Kendaraan Lain Melintas

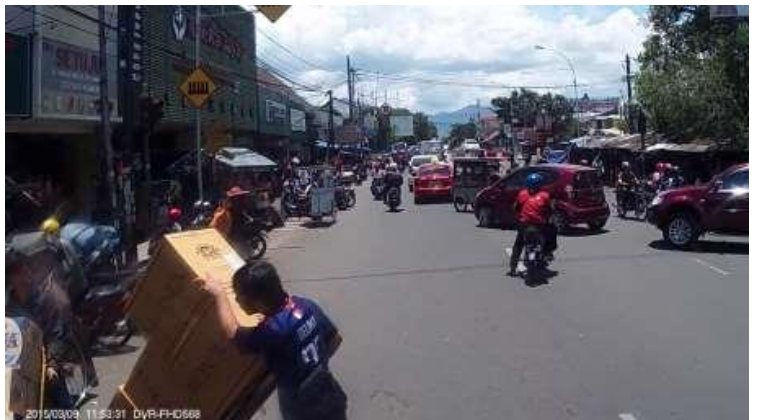

Gambar 3. Contoh Kejadian Crash-relevant Conflict untuk Menghindari Pejalan Kaki

Berbeda dengan penelitian sebelumnya, seperti yang dilakukan oleh Soccolich et al. (2013), dimana crash-relevant conflict justru muncul dalam frekuensi yang lebih rendah dibanding SCE jenis lain. Hal ini dikarenakan aktivitas berkendara yang diamati kebanyakan berlangsung di siang hingga malam hari. Sebagaimana diketahui, risiko kecelakaan lalu lintas dapat meningkat probabilitasnya pada malam hari (Wang, 2013).

Selanjutnya, SCE dalam kategori crash ditemukan sebanyak satu kali selama pengamatan, yaitu akibat sisi kiri bus yang mengenai sepeda motor yang muncul secara tiba-tiba saat bus berada di persimpangan jalan. Sementara itu SCE dolam kategori near crach tidak ditemukan selama pengamatan herlangsung 3.2. SCE Berdasarkan Penvebabnva

Di sisi lain, kejadian SCE dapat pula
dikelompokkan berdasarkan penyebab terjadinya, sebagaimana yang dicontohkan oleh Dingus et al. (2006). Beberapa penyebab terjadinya SCE yang sesuai dengan penelitian ini adalah obstacle present, other vehicle present, dan judgement error. Jumlah kejadian SCE berdasarkan penyebab terjadinya ditunjukkan pada Gambar 4.

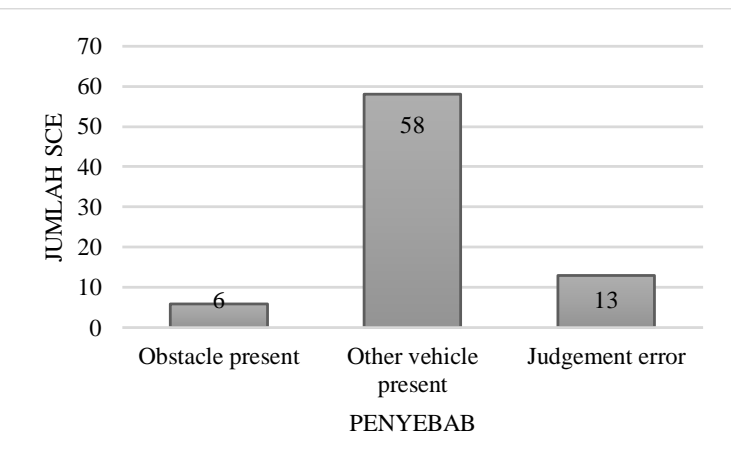

Gambar 4. Frekuensi SCE Berdasarkan Penyebabnya

Contoh kejadian SCE akibat kendaraan lain yang tiba-tiba berada di jalur yang akan dilalui bus sudah ditampilkan pada Gambar 2. Selanjutnya Gambar 5 menunjukkan contoh kejadian SCE akibat adanya kesalahan responden dalam menilai aman atau tidaknya suatu kondisi berkendara (judgement error). Penyebab yang paling jarang menimbulkan SCE adalah adanya 
objek selain kendaraan lain yang menghalangi jalur pengemudi (obstacle present). Beberapa SCE karena adanya objek lain adalah ketika pejalan kaki menyeberang secara tiba-tiba seperti yang sudah ditunjukkan pada Gambar 3.

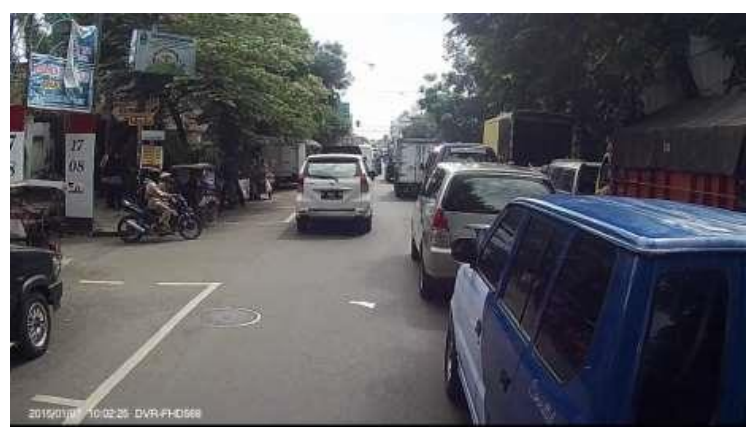

Gambar 5. Contoh Kejadian SCE Akibat Judgement Error

\subsection{SCE Berdasarkan Durasi Berkendara}

Sebagaimana yang disimpulkan dalam penelitian Di Milia et al. (2011), peningkatan durasi berkendara akan berakibat pada peningkatan risiko kecelakaan lalu lintas. Demikian halnya dengan SCE, yang mengalami risiko peningkatan sejalan dengan meningkatnya durasi berkendara seseorang, yang tercermin dalam Tabel 1.

Uji statistik Kruskall-Wallis kemudian digunakan untuk menguji perbedaan kemunculan SCE antar kelompok durasi berkendara. Hasil uji menunjukkan adanya perbedaan signifikan antar kemunculan SCE pada ketiga kelompok durasi berkendara tersebut $\left(\chi^{2}=32,155 ; \mathrm{df}=2\right.$; asymp. sig. $\left.=0.000\right)$. Oleh karena itu, durasi mengemudi dianggap mempengaruhi banyaknya SCE yang terjadi dan penting untuk dianalisis lebih lanjut, seperti yang disimpulkan pada penelitian Soccolich et al. (2012).

Uji statistik lanjutan dengan teknik Mann-Whitney kemudian dilakukan untuk mengetahui kelompok yang memberikan perbedaan signifikan tersebut. Hasil uji menunjukkan bahwa perbedaan signifikan ditunjukkan oleh perbandingan kelompok 1 (durasi 0-1 jam) dan kelompok 2 (durasi 1-2 jam) (Mann-Whitney $U=6,000$; asymp. sig. $=0,000)$, juga oleh perbandingan kelompok 1 dan 3 (durasi 2-3 jam) (Mann-Whitney $U=13,000$; asymp. sig.=0,000). Hasil uji ini menunjukkan bahwa terdapat perbedaan kemunculan SCE yang signifikan sebelum dan sesudah pengemudi berkendara selama satu jam. Hal ini ditunjukkan pula oleh Gambar 6, dimana terjadi peningkatan kemunculan SCE seiring dengan peningkatan waktu berkendara. Dengan demikian, titik waktu durasi berkendara selama satu jam ini menjadi penting. Istirahat yang memadai kualitas dan kuantitasnya harus disediakan setelah pengemudi berkendara selama satu jam non-stop. Hal ini dapat dilakukan secara berkesinambungan oleh pihak pengusaha bus dan pemerintah setempat.

Di sisi lain, pemerintah telah memberikan regulasi melalui PP RI Nomor 44 Tahun 1993 Pasal 240 yang menyatakan bahwa pengemudi kendaraan umum harus beristirahat sekurang-kurangnya 30 menit setelah mengemudikan kendaraan selama empat jam. Namun, hal ini belum dilakukan oleh para responden. Pada pukul 10.00-14.00, responden sebenarnya telah mengemudi selama kurang lebih 4 jam, walaupun terdapat beberapa waktu istirahat sejenak karena menunggu penumpang pada durasi tersebut, namun jumlahnya kurang dari 30 menit. Selain itu, peraturan internasional juga mengharuskan istirahat selama 45 menit penuh setelah mengemudi selama 4,5 jam (Vehicle \& Operator Services Agency, 2009). Hal ini berbeda dengan waktu istirahat yang dilakukan oleh responden, yaitu sekitar 15-30 menit ditambah dengan waktu istirahat pada pukul 12.00-13.00. Dengan demikian, peraturan pemerintah yang telah dikeluarkan perlu dievaluasi lebih lanjut. Perbaikan yang dapat dilakukan adalah menambahkan waktu istirahat pengemudi dan membatasi durasi mengemudi setiap pengemudi. Sesuai dengan hasil penelitian ini, pengemudi bus sebaiknya memiliki waktu istirahat atau berhenti sejenak setiap satu jam sekali dan waktu istirahat selama 30-45 menit setiap empat jam sekali.

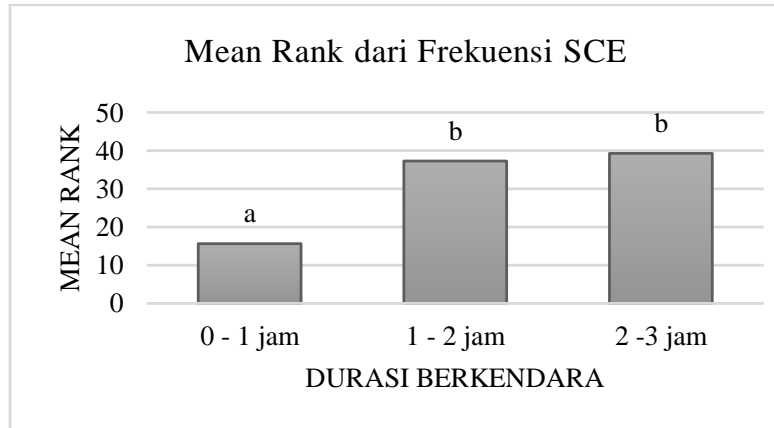

Gambar 6. Peningkatan Frekuensi SCE Seiring dengan Meningkatnya Durasi Berkendara

\subsection{SCE Berdasarkan Waktu Berkendara}

Kejadian SCE kemudian dikelompokkan juga berdasarkan waktu berkendara, seperti yang ditunjukkan pada Gambar 7. Dari ilustrasi tersebut terlihat bahwa jumlah SCE terbanyak ditemui pada jam berkendara antara pukul 11:00 sampai 12:00 waktu setempat. Kondisi ini sejalan dengan irama sirkadian (circadian rythm) manusia pada umumnya. Penurunan kondisi sirkadian ini berdampak pada penurunan kewaspadaan dan peningkatan kelelahan, sehingga mempertinggi risiko kejadian SCE.

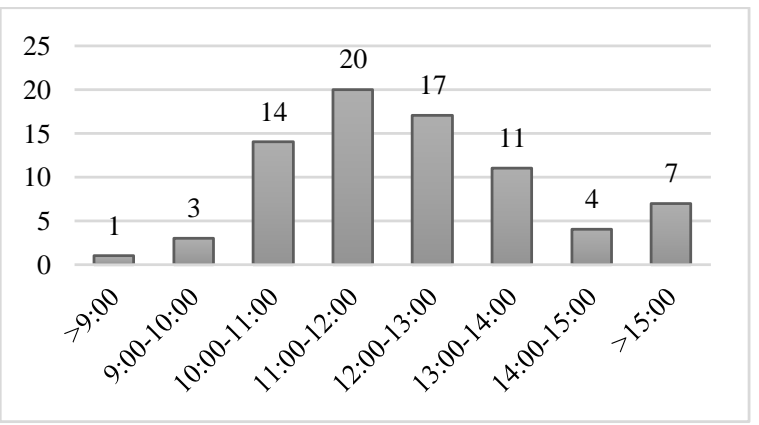

Gambar 7. Frekuensi SCE Berdasarkan Waktu Berkendara 
Uji statistik ANOVA dilakukan terhadap kemunculan SCE pada tiga kelompok waktu berkendara, yaitu pukul 06:00-10:00, pukul 10:0014:00, dan pukul 14:00-17:00. Hasil uji statistik tersebut menunjukkan adanya perbedaan yang signifikan antar SCE yang muncul pada setiap kelompok durasi berkendara $(\mathrm{F}=24,652 ; \mathrm{df}=2$; sig.=0.000). Hasil uji post-hoc lanjutan pada ketiga kelompok waktu berkendara tersebut menunjukkan bahwa SCE terbanyak signifikan muncul pada pukul 10:00-14:00.

Perbedaan jumlah terjadinya SCE berkaitan dengan performansi pengemudi yang menurun seiring dengan bertambahnya durasi mengemudi. Peraturan Pemerintah Republik Indonesia Nomor 44 tahun 1993 Pasal 240 menyatakan bahwa pengemudi kendaraan umum harus beristirahat sekurang- kurangnya 30 menit setelah mengemudikan kendaraan selama 4 jam. Namun, hal ini belum dilakukan oleh pengemudi bus DAMRI. Pada pukul 10.00-14.00, pengemudi telah mengemudi selama kurang lebih 4 jam, walaupun terdapat beberapa waktu istirahat karena menunggu penumpang pada durasi tersebut. Selain itu, pada pukul 10.00-14.00 terdapat waktu yang seharusnya digunakan untuk istirahat secara optimal.

Tingginya SCE pada pukul 10.00-14.00 dibandingkan dengan waktu lainnya juga dapat terjadi karena ritme sirkadian yang dialami pengemudi. Ritme sirkadian merupakan siklus jam tubuh yang dialami pengemudi selama 24 jam. Kelelahan dan kantuk pada seseorang biasa terjadi pada malam hari, menjelang pagi hari, dan siang hari. Kantuk mencapai tingkat tertinggi saat malam hari dan siang hari (Rail Safety and Standards Board, 2013). Oleh karena itu, saat siang hari, frekuensi SCE meningkat, yang disebabkan oleh kondisi tubuh pengemudi yang merasa lelah atau mengantuk.

\subsection{SCE Berdasarkan Lokasi Kejadian}

Pada rute panjang, frekuensi kejadian SCE yang lebih tinggi ditemukan pada saat responden berkendara di Jalan Ahmad Yani. Hasil rekapitulasinya ditunjukkan dengan diagram pada Gambar 8 . Sementara itu, frekuensi SCE pada rute pendek paling banyak ditemukan pada Jalan Ir. H. Djuanda (Jalan Dago) dan Jalan Kebon Kawung (Jalan Stasiun), sesuai hasil rekapitulasi pada Gambar 9.

Berdasarkan analisis lebih lanjut kemudian diketahui bahwa ketiga jalan ini kesamaan karakteristik. Pertama, jalan tersebut tergolong ramai oleh berbagai jenis kendaraan yang melintas, juga oleh para pejalan kaki. Ketiga jalan tersebut umumnya selalu ramai pada pagi dan sore hari, saat jam berangkat dan pulang kerja pegawai pada umumnya. Hal ini sesuai dengan penelitian terdahulu oleh Komada et al. (2013) yang menyimpulkan bahwa kondisi jalan yang ramai, khususnya oleh kendaraan lain, berpengaruh terhadap tingginya risiko kecelakaan. Kondisi jalan yang ramai dapat menyebabkan jarak antar kendaraan semakin kecil, sehingga risiko terjadinya SCE meningkat. Pernyataan ini diperkuat pula oleh hasil penelitian Sadeghniiat-Haghigi et al. (2015), yaitu bahwa kecelakaan yang terjadi di jalan raya meningkat saat kondisi jalan ramai dan menurun saat kondisi jalan sepi.

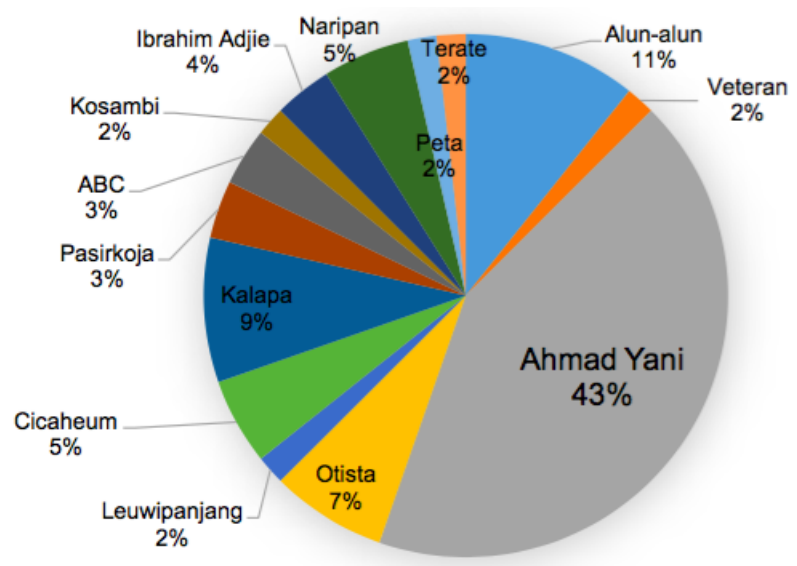

Gambar 8. Frekuensi SCE Berdasarkan Lokasi Kejadian pada Rute Panjang

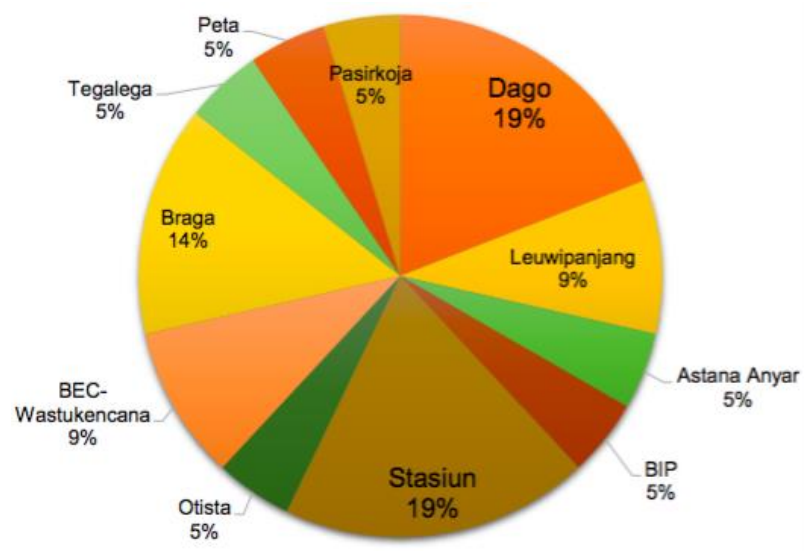

Gambar 9. Frekuensi SCE Berdasarkan Lokasi Kejadian pada Rute Pendek

Kesamaan karakteristik kedua, yaitu lokasi di sekitar ketiga jalanan tersebut yang tidak memiliki tempat pemberhentian, seperti halte, dalam jumlah cukup. Terkait dengan hal ini, maka tidak banyak penumpang yang naik ataupun turun di ketiga daerah tersebut. Dengan demikian, umumnya bus melaju dalam kecepatan yang relatif konstan pada ketiga jalan itu. Perhatian dapat diberikan oleh pengusaha bus dan pemerintah setempat dengan cara menyediakan tempat pemberhentian sementara (halte), agar pengemudi dapat mengembalikan fokus dan kewaspadaannya. Hal ini sejalan dengan pendapat Williamson et al. (2011), bahwa umumnya pengemudi dapat menilai secara mandiri apakah dirinya merasa lelah atau tidak. Ketika pengemudi merasa lelah, mereka dapat menggunakan tempat pemberhentian tersebut untuk istirahat sejenak.

Karakteristik ketiga, kondisi Jalan Dago dan Jalan Ahmad Yani cenderung lurus dan memiliki banyak persimpangan, seperti yang ditunjukkan secara berurutan oleh Gambar 10 dan Gambar 11. Hal ini 
menyebabkan tidak banyak manuver yang perlu dilakukan oleh pengemudi selama berkendara di jalanan tersebut. Pendapat ini sesuai pula dengan penelitian Kodaka et al. (2003) yang menyimpulkan bahwa $90 \%$ kejadian hampir celaka maupun kecelakaan terjadi di jalan yang lurus. Kondisi ini terjadi akibat penurunan kewaspadaan pengemudi akan kondisi jalanan dan kendaraan di sekitarnya. Selain itu, pemberhentian yang sedikit juga menyebabkan kewaspadaan pengemudi dalam berkendara menurun. Hal ini terjadi karena tidak ada intervensi yang dialami oleh pengemudi.

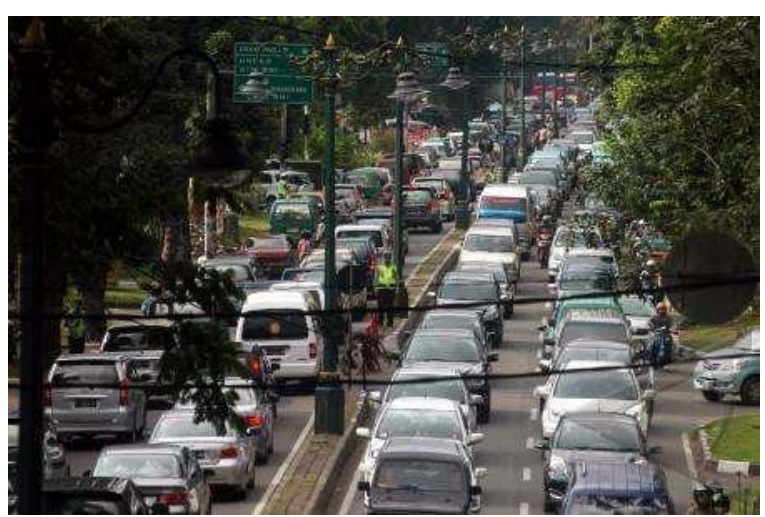

Gambar 10. Kondisi Jalan Ir. H. Djuanda (Dago)

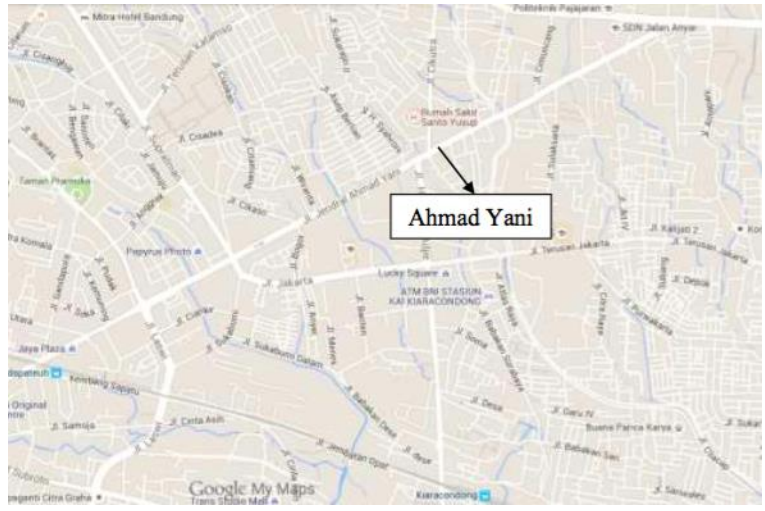

Gambar 11. Kondisi Jalan Ahmad Yani

\section{Kesimpulan}

Pengamatan naturalistik pada pengemudi bus kota menunjukkan kejadian safety critical event yang cukup tinggi. Jenis SCE yang paling banyak terjadi adalah berupa crash relevant conflict $(98,7 \%)$, yang ditandai dengan pengemudi yang mengerem mendadak akibat adanya kendaraan lain atau pejalan kaki yang melintas secara tiba-tiba di jalurnya. Kemunculan SCE ternyata dipengaruhi oleh durasi berkendara, waktu berkendara, dan karakteristik jalanan. Karena SCE signifikan muncul pada durasi berkendara di atas satu jam, maka setelah pengusaha bus atau pemerintah terkait harus memastikan para pengemudi beristirahat sejenak setelah berkendara non-stop selama satu jam. Selanjutnya, karakteristik jalanan yang relatif ramai, lurus, sedikit tempat pemberhentian, atau banyak persimpangan terbukti memunculkan SCE dalam jumlah yang signifikan lebih banyak.
Berdasarkan hasil tersebut, penelitian ini menyarankan agar rambu lalu lintas di persimpangan maupun di tempat yang potensial sebagai terjadinya SCE agar diperbanyak. Peraturan mengenai durasi berkendara dan istirahat agar diperbaharui, sehingga pengemudi tidak mengalami kelelahan berlebih yang dapat berakibat pada kecelakaan. Berdasarkan penelitian ini, pengemudi dapat berhenti sejenak setiap satu jam sekali dan beristirahat selama 30-45 menit setiap empat jam sekali. Jumlah tempat pemberhentian kendaraan (halte) sebaiknya dievaluasi, agar pengemudi dapat berhenti sejenak setiap berkendara kurang dari satu jam untuk mengembalikan kewaspadaan pengemudi.

\section{Ucapan Terima Kasih}

Terima kasih kepada Perum DAMRI Jawa Barat atas ijin yang diberikan, beserta semua pengemudi bus yang terlibat dalam penelitian ini.

\section{Daftar Pustaka}

Biggs, H. C., Dingsdag, D. P., \& Stenson, N. (2009). Fatigue factors affecting metropolitan bus drivers: A qualitative investigation. Work: A Journal of Prevention, Assessment, and Rehabilitation, 32 (1). 5-10.

Di Milia, L., Smolensky, M. H., Costa, G., Howarth, H. D., Ohayon, M. M., \& Philip, P. (2011). Demographic factors, fatigue, and driving accidents: An examination of the published literature. Accident Analysis and Prevention, 43, 516-532.

Dingus, T. A., Neale, V. L., Klauer, S. G., Petersen, A. D., \& Carrol, R. J. (2006). The development of a naturalistic data collection system to perform critical incident analysis: An investigation of safety and fatigue issues in long-haul trucking. Accident Analysis and Prevention, 38, 1127-1136.

Kodaka, K., Otabe, M., Urai, Y., \& Koike, H. (2003). Rear-end collision avoidance assist system. Proceedings of 18th International Technical Conference on The Enhanced Safety of Vehicle. Nagoya: National Highway Traffic Safety Administration.

Komada, Y., Asaoka, S., Abe, T., \& Inoue, Y. (2013). Short sleep duration, sleep disorders, and traffic accidents. IATSS Research. 37. 1-7.

Mahachandra, M., Yassierli, Sutalaksana, I. Z., \& Ridwan, A. S. (2009). Changes in drowsiness level while driving on highway: Results of a naturalistic study in Indonesia. The 10th Asia Pacific Industrial Engineering \& Management Systems Conference (APIEMS), 14-16 Desember 2009, Kitakyushu, Fukuoka.

National Transport Commission. (2007). Model Legislation-Heavy Vehicle Driver Fatigue Regulations. Melbourne: National Transport Commission.

Rail Safety and Standards Board. (2013). Driving for Work: Managing Fatigue Risks, A Guide for Road 
Vehicle Drivers and Their Managers. Didapat dari http://www.rssb.co.uk/Library/improving-industryperformance/2013guide- t997-driving-for-worka5.pdf.

Sadeghniiat-Haghighi, K., Yazdi, Z., Moradinia, M., Aminian, O., \& Esmaili, A. (2015). Traffic crash accidents in Tehran, Iran: Its relation with circadian rhythm of sleepiness. Chinese Journal of Traumatology. 18. 13-17.

Soccolich, S. A., Blanco, M., Hanowski, R. J., Olson, R. L., Morgan, J. F., Guo, F., \& Wu, S. (2012). An analysis of driving and working hour on commercial motor vehicle driver safety using naturalistic data collection. Accident Analysis and Prevention, 58, 249-258.

Tseng, C. (2011). Social-demographic, driving experience and yearly driving distance in relation to a tour bus driver's at-fault accident risk. Tourism Management, 33. 910-915.
Vehicle \& Operator Services Agency. (2009). Rules on Drivers' Hours and Tachographs. Diakses pada https://www.gov.uk/- government/uploads/system/uploads/attachment_data/file/208091/rules-ondrivers-hours-and-tacho-graphs-goods-vehicles-ingb-and-europe.pdf.

Wang, C., Quddus, M. A., \& Ison, S. G. (2013). The effect of traffic and road characteristics on road safety: A review and future research direction. Safety Science, 57, 264-275.

Williamson, A., Lombardi, D. A., Folkard, S., Stutts, J., Courtney, T. K., \& Connor, J. L. (2011). The link between fatigue and safety. Accident Analysis and Prevention, 43, 498-515.

Yassierli, Mahachandra, M., \& Sutalaksana, I. Z. (2015). Fatigue evaluation of fuel truck drivers. Procedia Manufacturing, 4, 352-358. 